ORIGINAL ARTICLE

\title{
A randomised controlled trial of postural interventions for prevention of musculoskeletal symptoms among computer users
}

\author{
F Gerr, M Marcus, C Monteilh, L Hannan, D Ortiz, D Kleinbaum
}

Occup Environ Med 2005;62:478-487. doi: 10.1136/oem.2004.015792

See end of article for authors' affiliations

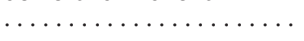

Correspondence to: Dr F Gerr, Department of Occupational and Environmental Health, 100 Oakdale Campus, College of Public Health, University of lowa, lowa City, IA 52242, USA; fred-gerr@ viowa.edu

Accepted 15 January 2005

\begin{abstract}
Aims: To examine the effect of two workstation and postural interventions on the incidence of musculoskeletal symptoms among computer users.

Methods: Randomised controlled trial of two distinct workstation and postural interventions (an alternate intervention and a conventional intervention) among 376 persons using computer keyboards for more than 15 hours per week. The incidence of neck/shoulder symptoms and hand/arm symptoms during six months of follow up among individuals in the intervention groups was compared to the incidence in computer users who did not receive an intervention (comparison group). For individuals in the intervention groups, study staff adjusted workstations, where possible, and trained individuals to assume the intervention postures. Individuals reported musculoskeletal symptoms in a weekly diary. Participants who reported discomfort intensity of 6 or greater on a 0-10 visual analogue scale or who reported musculoskeletal symptoms requiring use of analgesic medication were considered symptomatic.

Results: There were no significant differences in the incidence of musculoskeletal symptoms among the three intervention groups. Twenty two (18.5\%) participants in the alternate intervention group, 25 (20.2\%) in the conventional intervention group, and $25(21.7 \%)$ in the comparison group developed incident arm or hand symptoms. Thirty eight (33.3\%) participants in the alternate intervention group, $36(31.0 \%)$ in the conventional intervention group, and $33(30.3 \%)$ in the comparison group developed incident neck or shoulder symptoms. Compliance with all components of the intervention was attained for only $25-38 \%$ of individuals, due mainly to the inflexibility of workstation configurations.

Conclusions: This study provides evidence that two specific workplace postural interventions are unlikely to reduce the risk of upper extremity musculoskeletal symptoms among computer users.
\end{abstract}

\section{METHODS}

This was an intervention study of musculoskeletal symptoms among newly hired persons working with a computer workstation in office settings. Participants were recruited from among several large employers in metropolitan Atlanta, Georgia (USA). The Emory University Human Investigations Committee approved the study protocol and written informed consent was obtained from all participants at the time of enrolment.

\section{Study participant eligibility and recruitment procedures}

Participating organisations included insurance and financial companies, food product producers, and universities. At each of the participating organisations, a newly hired worker eligible for participation in the study was one who: (1) anticipated using a single computer workstation for 15 hours or more per week; and (2) anticipated using a computer workstation for at least as many hours per week as in his/her previous job. No other criteria were used to determine eligibility for participation. Those who had upper extremity musculoskeletal symptoms in a given anatomic location at the time of entry were excluded from follow up to incident symptoms of that location. Potential participants who reported discomfort in both the neck/shoulder and hand/ arm of intensity 6 or greater on a $0-10$ visual analogue scale

Abbreviations: $\mathrm{Cl}$, confidence interval; $\mathrm{HR}$, hazard ratio; MSD, musculoskeletal disorder; UEMSD, upper extremity musculoskeletal disorder; VAS, visual analogue scale 


\section{Main message}

- No differences in risk of musculoskeletal symptoms were observed among participants randomly assigned to two workstation and postural interventions in comparison to participants who received no workstation or postural intervention.

or who reported musculoskeletal symptoms for which they took analgesic medication were excluded from the study.

\section{Data collection instruments and procedures} Demographic and personal health history questionnaire

At the time of enrolment, study participants were asked to complete a questionnaire about past musculoskeletal symptoms and disorders, past or current illness potentially associated with musculoskeletal or neurological impairment (for example, arthritis, diabetes, thyroid illness), medication use, tobacco use, and past occupational computer use.

\section{Weekly exposure and symptom diary}

At the time of enrolment, participants were instructed on the use of a data collection instrument (the exposure and symptom diary) designed to obtain information about their work, symptoms of pain or discomfort, and non-occupational activities. Information was recorded daily about hours worked in the office, hours spent keying, and number of short ( $\leqslant 10$ minutes) and long (>10 minutes) breaks from the workstation.

On the same instrument, participants recorded information weekly about discomfort of the upper limbs, neck, and shoulder. Participants who experienced discomfort also indicated the intensity of the discomfort on a $0-10$ visual analogue scale (VAS), whether he/she took medication (for example, Tylenol, Motrin, etc) for it, and answered the question "What do you think caused the pain?". Questions designed to quantify time spent in aerobic and hand intensive activities were also included on the exposure and symptom diary. Study participants were asked to record information on the diary every day that they were enrolled in the study. The diaries were collected weekly and reviewed by study personnel.

\section{Occupational psychosocial questionnaire}

The Job Content Questionnaire ${ }^{8}$ was used to assess occupational psychosocial stress. The questionnaire was distributed to participants at the time of assignment to an intervention group. Domains examined included skill discretion, decision authority, decision latitude, psychological job demands, job strain, supervisor support, and co-worker support.

\section{Ergonomic assessment procedures}

Using a standard checklist, each workstation was evaluated for presence of specific items (for example, mouse or other pointing device), and the adjustability of specific equipment. Following completion of the checklist, dimensional and angular measurements (for example, seated elbow height, table surface height, keyboard inner elbow angle) were recorded.

\section{Intervention procedures}

Study participants were randomly assigned to one of three postural intervention groups: the alternate intervention (group A), the conventional intervention (group B), and the no

\section{Policy implications}

- The study provides no empirical basis for recommendation of one posture versus another for prevention of musculoskeletal symptoms among computer users.

intervention group (group C). Details of the interventions are described below.

Randomisation occurred following evaluation of workplace and ergonomic variables. The use of a random number table assured that each subject entering the study had an equal probability of being assigned to each of the three groups. ${ }^{9}$ Randomisation was done in blocks of six to assure equal numbers of participants in each of the study groups.

The alternate intervention was based on protective factors for both neck/shoulder and hand/arm symptoms identified during preliminary analyses of results from a prospective study of musculoskeletal disorders. ${ }^{10}$ The requirements of the alternate intervention were:

- Head tilt angle* less than or equal to $3^{\circ}$

- Head rotation less than $15^{\circ}$ in either direction (L/R)

- J key at least $2 \mathrm{~cm}$ below elbow height

- Keyboard inner elbow angle of $\geqslant 120^{\circ}$

- J key at least $12.5 \mathrm{~cm}$ from edge of desk or work surface

- Keyboard wrist ulnar deviation of $0^{\circ}$ to $-20^{\circ}$ (that is, up to $20^{\circ}$ radial deviation)

- Armrest present

- Keyboard wrist rest present

- Mouse wrist ulnar deviation of $-5^{\circ}$ to $5^{\circ}$

- Mouse wrist extension of $20^{\circ}$ to $30^{\circ}$

- Mouse next to keyboard

- High quality chair present**

The conventional intervention was based on recommendations from a number of sources, including OSHA, NIOSH, and private industry. The requirements of the conventional intervention were:

- Eye height level with top of monitor screen

- Head rotation less than $15^{\circ}$ in either direction ( $\left.\mathrm{L} / \mathrm{R}\right)$

- J key at least $3 \mathrm{~cm}$ above elbow height

- Keyboard shoulder flexion of $-10^{\circ}$ to $20^{\circ}$

- Keyboard shoulder abduction of $-10^{\circ}$ to $20^{\circ}$

- Keyboard inner elbow angle of $80^{\circ}$ to $100^{\circ}$

- Keyboard wrist ulnar deviation of $-10^{\circ}$ to $10^{\circ}$

- Keyboard wrist extension of $-10^{\circ}$ to $10^{\circ}$

- Keyboard wrist rest present

- Mouse wrist ulnar deviation of $-10^{\circ}$ to $10^{\circ}$

- Mouse wrist extension of $-10^{\circ}$ to $10^{\circ}$

- Armrest present

- High quality chair present

* Head tilt angle is defined as the angle formed between a line defined by the tragion of the ear and the infraorbitale of the eye and the horizon. To clarify the meaning of head tilt angle values, increasing neck extension results in larger values for head tilt angle and increasing neck flexion results in smaller (including negative) values.

**Characteristics of high quality chair: easily (pneumatically) adjustable for height, adjustable height backrest, full contoured backrest, adjustable seat pan angle, round waterfall seatpan edge, five legged base. ${ }^{10 a}$ 
Participants in group C (the no intervention group) were instructed to continue keying in their usual posture and no changes were made to their workstations.

A study staff member reconfigured the subject's workstation if the subject was randomly assigned to either the alternative or conventional interventions (groups A or B). First, if the " $\mathrm{J}$ " key was located less than $12.5 \mathrm{~cm}$ from the edge of the desk, the keyboard was moved so that the " $\mathrm{J}$ " key was $12.5 \mathrm{~cm}$ from the edge of the desk. Masking tape was applied to the work surface to provide a visual reference for the intervention position of the keyboard. Following placement of the keyboard, the participant's chair was replaced if it did not meet chair quality criteria (see second footnote). The chair height was then set to achieve both the required shoulder flexion angle and the required difference between elbow height and " $\mathrm{J}$ " key height for the respective intervention group. The armrests of the chair were adjusted to support the arms. Once the chair and upper extremity were configured properly, the monitor was moved to minimise head rotation and to produce the required head tilt angle. To achieve the required head tilt angle the monitor was placed on risers or removed from atop the PC CPU. If these steps did not produce the required intervention posture, other steps (that is, raising or lowering desks, etc) were taken to achieve them. However, in many instances, workstations could not be easily modified and complete compliance with the intervention posture was not achieved.

When placing participants in the intervention postures, a 6 inch goniometer (North Coast Medical, Inc., San Jose, CA) was used to measure wrist angles, and a 12 inch goniometer (North Coast Medical, Inc., San Jose, CA) was used to measure shoulder, elbow, and head and neck angles. All postural angles were recorded to the nearest degree. Goniometer pivot and arm placements for each of the postural measurements have been described previously. ${ }^{11}{ }^{12}$

Verbal and written instructions describing the desired posture were provided to all group A and B participants. Furthermore, study staff discussed with each participant in these groups the importance of maintaining the desired posture for the study period.

At three days and one week after the intervention, study staff returned to the participant's workplace to check on continued maintenance of the posture. If the posture had changed from the intervention, additional workstation changes were made and additional instruction given.

\section{Health outcomes assessment}

The occurrence of musculoskeletal symptoms was assessed at entry into the study and weekly thereafter. Study participants were asked if they experienced "any discomfort such as pain, aching, burning, numbness or tingling in your neck, shoulders, elbows/forearms, hands/wrists, or fingers". Those who experienced discomfort were asked to indicate the location of the discomfort (neck or shoulders versus arm or hand) and to rate the severity of the worst discomfort during the previous week on a $0-10$ VAS. Separate VAS were used to rate discomfort of the neck or shoulder and the forearm or hand. In addition, the question "Did you take any medication for this discomfort this past week?" was asked separately for the neck or shoulder and for the hand or arm. Study participants were classified as having experienced musculoskeletal symptoms if they (1) reported musculoskeletal discomfort on any day of the week with a severity of 6 or greater on the VAS or (2) reported musculoskeletal discomfort on any day of the week for which they took medication (overthe-counter or prescription). The occurrence of symptoms was determined separately for the neck or shoulder and for the hand or arm. Study participants were followed for each outcome separately until they became symptomatic, withdrew from the study, or completed six months of follow up. Development of a symptom in one anatomic area did not stop the collection of data for the other anatomic area.

\section{Statistical analyses}

All analyses were performed using the SAS statistical package (SAS Institute, Carey, NC). Incidence rates of neck or shoulder symptoms and of arm or hand symptoms were calculated separately for each of the three intervention arms of the study. Participants contributed data to their assigned intervention group regardless of compliance (that is, data were analysed by "intention to treat").

For the purpose of calculating follow up rates, persons were classified as full follow up if they remained in the study for the entire duration of their eligibility period. For most participants, this occurred either when they completed six months of follow up while free of symptoms or when they developed a symptom that met the study case definition. A few participants became ineligible for the study prior to six months time or symptom onset because they either left the participating company or experienced trauma of the limb. These few participants were also classified as full follow up. Those who discontinued participation while still eligible for follow up were classified as incomplete follow up and included those who refused the assigned study posture, discontinued participation because they were "too busy" or for no given reason, or did not complete study forms.

Kaplan-Meier survival curves and relative risks for each of the three groups were calculated using survival analysis methodology. ${ }^{13} 14$ Survival time was taken as the time to incident symptoms. Those participants who left the study without manifesting the outcome were censored at the time they left and contributed person-time until they were censored. For each outcome, the three survival curves generated by the Kaplan-Meier method were compared using the log rank test. ${ }^{15}$ In addition, because some independent variables were time varying, relative risks were estimated using an extension of Cox's hazard models (PHREG, SAS Institute $^{15}$ ) with time to incident symptoms as the dependent variable and intervention group as the independent variable. Adjustment for ties was made with the exact method. ${ }^{14}$

\section{Confounding variables}

Time invariant variables examined for potential confounding of the relation between intervention group and incident symptoms were age, gender, history of arm or hand symptoms, history of neck or shoulder symptoms, medication use, history of arthritis or rheumatism, "slipped" or "ruptured" intervertebral disc, self-reported typing speed, self-reported level of mouse use, job category, ability to step away from the workstation at any time, and chair comfort. Time varying variables examined for potential confounding were hours per week in office, hours per week keying, weekly report of job stress, hours per week of aerobic activity, and hours per week of hand intensive activity.

Differences in distributions of potentially confounding variables were examined across the three intervention groups. Categorical data were examined using a $\chi^{2}$ test and continuous data were examined using analysis of variance. Characteristics that differed across intervention groups with a probability of $>0.30$ were excluded from further consideration of confounding potential. Remaining variables (those with $p \leqslant 0.30$ ) were then assessed by a process of sequential backward elimination designed to retain possible confounders, the elimination of which changed the hazard ratios of the intervention groups by more than $10 \%$. 


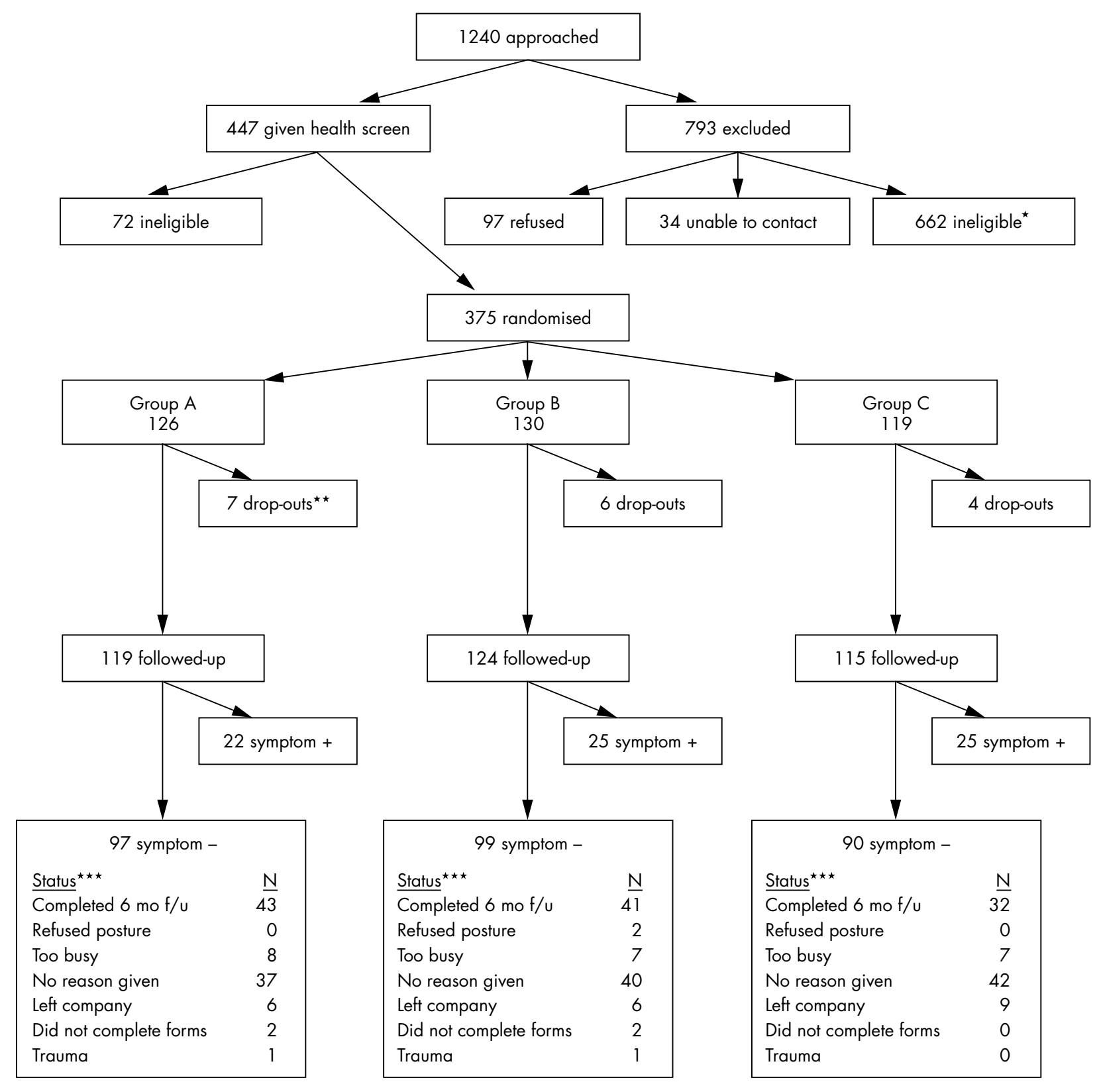

$\star$ Reasons for ineligibility are provided in the text

$\star \star 1$ ineligible after randomisation

$\star \star \star$ Not all symptom negative participants completed six months of follow-up. The status at time of study exit of all participants who did not meet criteria for positive symptoms during follow-up is enumerated in the box.

Figure 1 Arm and hand cohort flow chart.

\section{RESULTS}

\section{Recruitment and randomisation}

Figures 1 and 2 show the flow of participants. A total of 1240 individuals were contacted to determine eligibility. Of these, 793 individuals were excluded, with 447 potential participants remaining. Of those excluded, 662 were ineligible, 34 could not be contacted, and 97 refused to participate. The majority of the ineligibles worked too few hours with a computer $(\mathrm{n}=239)$ or used multiple computers at work $(\mathrm{n}=147)$. Additional individuals were ineligible because they reportedly used a second computer at home for more than
20 hours per week $(n=116)$, used a laptop computer at work $(\mathrm{n}=30)$, did not use a computer at work $(\mathrm{n}=43)$, were out of town $(n=14)$, or met additional a priori defined exclusion criteria related to availability or computer use $(n=73)$.

Two separate, overlapping cohorts were then defined to examine separately the risks of neck or shoulder symptoms and the risks of arm or hand symptoms. Ninety one individuals were ineligible for inclusion in the neck or shoulder cohort because they reported experiencing neck or shoulder symptoms during the week prior to entry, and 72 individuals were excluded from the arm or hand cohort 


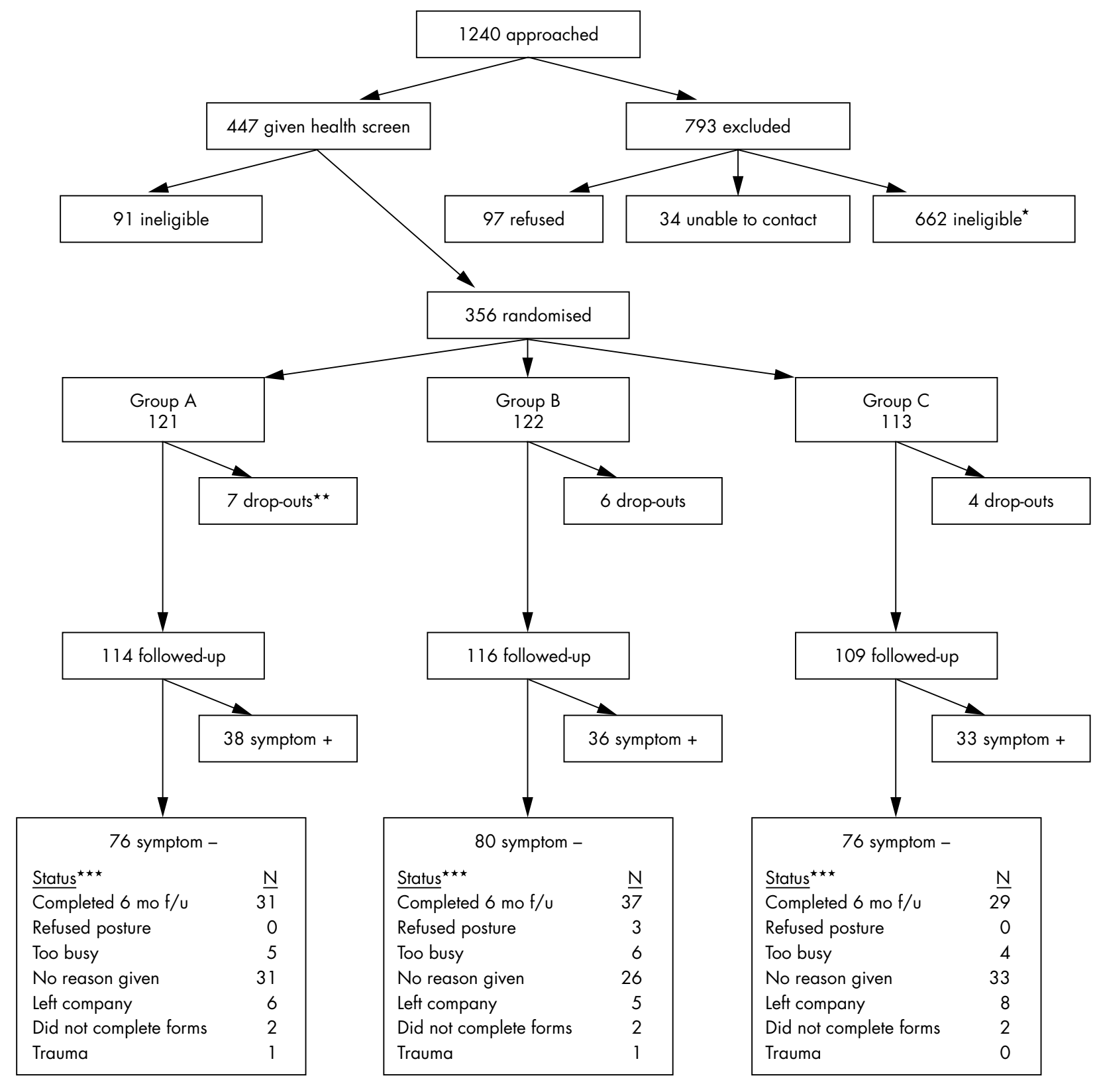

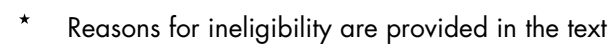

$\star \star 1$ ineligible after randomisation

$\star \star \star$ Not all symptom negative participants completed six months of follow-up. The status at time of study exit of all participants who did not meet criteria for positive symptoms during follow-up is enumerated in the box.

Figure 2 Neck and shoulder cohort flow chart.

because they reported experiencing arm or hand symptoms during the week prior to entry.

A total of 379 individuals who were eligible for inclusion in one or both cohorts were randomised into one of the three intervention groups. For those at risk of incident arm or hand symptoms $(\mathrm{n}=375), 126$ were randomised into group $\mathrm{A}, 130$ into group B, and 119 into group C. After randomisation, seven participants in group A dropped out of the study as did six in group B, and four in group C. As a result, 119 participants in group A, 124 in group B, and 115 in group C were followed for incident hand or arm symptoms $(n=358)$.
For those at risk of incident neck or shoulder symptoms $(\mathrm{n}=356), 121$ were randomised into group A, 122 into group $\mathrm{B}$, and 113 into group C. After randomisation, seven in group A dropped out of the study as did six in group B, and four in group C. As a result, 114 individuals in group A, 116 in group $\mathrm{B}$, and 109 in group $\mathrm{C}$ were followed for neck or shoulder symptoms $(\mathrm{n}=339)$.

The randomisation was relatively successful in creating intervention groups with similar demographics (table 1), current and past medical conditions (table 2), and occupational characteristics (tables 3 and 4 ). The only exceptions 


\begin{tabular}{|c|c|c|c|c|c|c|c|}
\hline & \multicolumn{6}{|c|}{ Intervention group } & \multirow[b]{3}{*}{$p$ value } \\
\hline & \multicolumn{2}{|c|}{$A(n=122)$} & \multicolumn{2}{|c|}{$B(n=125)$} & \multicolumn{2}{|c|}{$C(n=115)$} & \\
\hline & $\mathbf{n}$ & $\%$ & $\mathrm{n}$ & $\%$ & $\mathbf{n}$ & $\%$ & \\
\hline \multicolumn{8}{|l|}{ Age } \\
\hline $18-24$ & 19 & (15.6) & 24 & (19.2) & 25 & (21.7) & \multirow{5}{*}{0.98} \\
\hline $25-34$ & 59 & (48.4) & 56 & $(44.8)$ & 52 & (45.2) & \\
\hline $35-44$ & 29 & (23.8) & 30 & (24.0) & 26 & (22.6) & \\
\hline $45-54$ & 13 & (10.7) & 12 & $(9.6)$ & 10 & $(8.7)$ & \\
\hline $55+$ & 2 & $(1.6)$ & 3 & (2.4) & 2 & (1.7) & \\
\hline \multicolumn{8}{|l|}{ Gender } \\
\hline Male & 30 & (24.6) & 28 & (22.4) & 25 & $(21.7)$ & \multirow[t]{2}{*}{0.86} \\
\hline Female & 92 & (75.4) & 97 & (77.6) & 90 & (78.3) & \\
\hline \multicolumn{8}{|l|}{ Ethnicity } \\
\hline White, not of Hispanic origin & 68 & (56.6) & 68 & $(55.7)$ & 74 & (66.1) & \multirow[t]{3}{*}{0.21} \\
\hline Other & 52 & (43.3) & 54 & (44.3) & 38 & (33.9) & \\
\hline Missing & 2 & & 3 & & 3 & & \\
\hline \multicolumn{8}{|l|}{ Education-college graduate } \\
\hline Yes & 93 & (77.5) & 79 & (64.8) & 86 & (76.8) & \multirow[t]{3}{*}{0.04} \\
\hline No & 27 & (22.5) & 43 & (35.3) & 26 & (23.2) & \\
\hline Missing & 2 & & 3 & & 3 & & \\
\hline \multicolumn{8}{|l|}{ Current smoker } \\
\hline No & 107 & (89.2) & 112 & (91.8) & 105 & (93.8) & \multirow[t]{3}{*}{0.45} \\
\hline Yes & 13 & $(10.8)$ & 10 & (8.2) & 7 & (6.3) & \\
\hline Missing & 2 & & 3 & & 3 & & \\
\hline \multicolumn{8}{|l|}{ Hand dominance } \\
\hline Left handed & 9 & $(7.5)$ & 13 & $(10.7)$ & 9 & $(8.0)$ & \multirow[t]{3}{*}{0.65} \\
\hline Right handed & 111 & (92.5) & 109 & (89.3) & 103 & (92.0) & \\
\hline Missing & 2 & & 3 & & 3 & & \\
\hline \multicolumn{8}{|l|}{ Income } \\
\hline Less than $\$ 35000$ & 36 & $(30.8)$ & 49 & $(40.5)$ & 39 & $(35.8)$ & \multirow[t]{3}{*}{0.61} \\
\hline$\$ 35000-\$ 74999$ & 53 & (45.3) & 48 & (39.7) & 44 & $(40.4)$ & \\
\hline$\$ 75000$ and over & 28 & (23.9) & 24 & (19.8) & 26 & (23.9) & \\
\hline Missing & 5 & & 4 & & 6 & & \\
\hline \multicolumn{8}{|l|}{ BMI-males } \\
\hline$<25$ & 14 & $(46.7)$ & 14 & $(50.0)$ & 16 & (64.0) & \multirow[t]{3}{*}{0.14 (FE) } \\
\hline $25-29.9$ & 9 & (30.0) & 13 & (46.4) & 7 & (28.0) & \\
\hline $30+$ & 7 & (23.3) & 1 & (3.6) & 2 & (8.0) & \\
\hline \multicolumn{8}{|l|}{ BMI-females } \\
\hline$<25$ & 54 & $(58.7)$ & 58 & $(59.8)$ & 59 & (65.6) & \multirow[t]{3}{*}{0.33} \\
\hline $25-29.9$ & 28 & (30.4) & 22 & (22.7) & 23 & (25.6) & \\
\hline $30+$ & 10 & (10.9) & 17 & (17.5) & 8 & (8.9) & \\
\hline
\end{tabular}

were measures of education, chair comfort, and stress. Participants in groups A and C were significantly more likely to be college graduates than those in group B. Participants in groups A and B were significantly more likely to judge their chairs as comfortable than those in group C. However, this is not unexpected, as chair comfort was assessed after randomisation and low quality chairs used by participants in groups $\mathrm{A}$ and $\mathrm{B}$ had been replaced. There were no

Table 2 Current and past medical conditions by intervention group

\begin{tabular}{|c|c|c|c|c|c|c|c|}
\hline & \multicolumn{6}{|c|}{ Intervention group } & \multirow[b]{3}{*}{ p value } \\
\hline & \multicolumn{2}{|c|}{$A(n=122)$} & \multicolumn{2}{|c|}{$B(n=125)$} & \multicolumn{2}{|c|}{$C(n=115)$} & \\
\hline & n & $\%$ & n & $\%$ & $\mathrm{n}$ & $\%$ & \\
\hline \multicolumn{8}{|c|}{ History hand/arm disorder past 3 years (medication and/or intensity $\geqslant 6$ ) } \\
\hline No & 99 & (82.5) & 101 & (82.8) & 87 & (77.7) & \multirow[t]{3}{*}{0.54} \\
\hline Yes & 21 & (17.5) & 21 & (17.2) & 25 & (22.3) & \\
\hline Missing & 2 & & 3 & & 3 & & \\
\hline \multicolumn{8}{|c|}{ History neck/shoulder disorder past 3 years (medication and/or intensity $\geqslant 6$ ) } \\
\hline No & 79 & (65.8) & 81 & (66.4) & 65 & $(58.0)$ & \multirow[t]{3}{*}{0.34} \\
\hline Yes & 41 & (34.2) & 41 & (33.6) & 47 & $(42.0)$ & \\
\hline Missing & 2 & & 3 & & 3 & & \\
\hline \multicolumn{8}{|c|}{ Neck/shoulder symptomatic at time of entry } \\
\hline No & 114 & (93.4) & 116 & (92.8) & 109 & (94.8) & \multirow[t]{2}{*}{0.82} \\
\hline Yes & 8 & (6.6) & 9 & (7.2) & 6 & (5.2) & \\
\hline \multicolumn{8}{|c|}{ Hand/arm symptomatic at time of entry } \\
\hline No & 120 & (98.4) & 124 & (99.2) & 115 & $(100.0)$ & \multirow[t]{2}{*}{0.66 (FE) } \\
\hline Yes & 2 & $(1.6)$ & 1 & $(0.8)$ & 0 & $(0.0)$ & \\
\hline \multicolumn{8}{|c|}{ Symptomatic body part: screener } \\
\hline N/S only & 8 & (6.6) & 9 & (7.2) & 6 & (5.2) & \multirow[t]{3}{*}{0.78 (FE) } \\
\hline H/A only & 2 & $(1.6)$ & 1 & (0.8) & 0 & $(0.0)$ & \\
\hline Neither & 112 & (91.8) & 115 & (92.0) & 109 & (94.8) & \\
\hline
\end{tabular}


Table 3 Occupational characteristics by intervention group

\begin{tabular}{|c|c|c|c|c|c|c|c|}
\hline & \multicolumn{6}{|c|}{ Intervention group } & \multirow[b]{3}{*}{ p value } \\
\hline & \multicolumn{2}{|c|}{$A(n=122)$} & \multicolumn{2}{|c|}{$B(n=125)$} & \multicolumn{2}{|c|}{$C(n=115)$} & \\
\hline & $\mathbf{n}$ & $\%$ & $\mathbf{n}$ & $\%$ & $n$ & $\%$ & \\
\hline \multicolumn{8}{|l|}{ Typing speed } \\
\hline$<50$ wpm & 45 & (38.5) & 36 & $(30.5)$ & 42 & $(41.2)$ & 0.34 \\
\hline 50-60 wpm & 55 & (47.0) & 67 & (56.8) & 44 & (43.1) & \\
\hline$>65$ wpm & 17 & (14.5) & 15 & (12.7) & 16 & (15.7) & \\
\hline Missing & 5 & & 5 & & 13 & & \\
\hline \multicolumn{8}{|l|}{ Job title } \\
\hline Officials and managers & 6 & $(5.1)$ & 9 & $(7.6)$ & 9 & $(8.8)$ & 0.84 (FE) \\
\hline Professionals & 66 & $(56.4)$ & 54 & $(45.8)$ & 54 & (52.9) & \\
\hline Technicians & 2 & $(1.7)$ & 3 & $(2.5)$ & 2 & $(2.0)$ & \\
\hline Sales & 1 & $(0.9)$ & 1 & $(0.9)$ & 1 & $(1.0)$ & \\
\hline Office and clerical & 42 & (35.9) & 51 & (43.2) & 36 & (35.3) & \\
\hline Missing & 5 & & 7 & & 13 & & \\
\hline \multicolumn{8}{|l|}{ Use a mouse } \\
\hline Sometimes & 5 & $(4.3)$ & 5 & $(4.2)$ & 3 & $(2.9)$ & 0.94 (FE) \\
\hline Frequently & 47 & $(40.2)$ & 50 & $(42.4)$ & 39 & (38.2) & \\
\hline Almost all the time & 65 & $(55.6)$ & 63 & (53.4) & 60 & $(58.8)$ & \\
\hline Missing & 5 & & 7 & & 13 & & \\
\hline \multicolumn{8}{|l|}{ Step away from workstation } \\
\hline When you choose & 114 & (97.4) & 117 & (99.2) & 99 & (97.1) & 0.52 (FE) \\
\hline Scheduled times & 3 & $(2.6)$ & 1 & $(0.9)$ & 3 & $(2.9)$ & \\
\hline Missing & 5 & & 7 & & 13 & & \\
\hline \multicolumn{8}{|l|}{ JCQ job strain quadrant } \\
\hline High strain quadrant & 21 & (18.0) & 23 & (19.5) & 25 & (24.5) & 0.46 \\
\hline Non-high strain quadrant & 96 & (82.1) & 95 & (80.5) & 77 & (75.5) & \\
\hline Missing & 5 & & 7 & & 13 & & \\
\hline \multicolumn{8}{|l|}{ Chair comfort } \\
\hline Very comfortable & 56 & (47.9) & 52 & $(44.1)$ & 24 & (23.5) & 0.00 (FE) \\
\hline Somewhat comfortable & 54 & $(46.2)$ & 59 & $(50.0)$ & 60 & $(58.8)$ & \\
\hline Somewhat uncomfortable & 6 & $(5.1)$ & 5 & $(4.2)$ & 16 & $(15.7)$ & \\
\hline Very uncomfortable & 1 & $(0.9)$ & 2 & $(1.7)$ & 2 & $(2.0)$ & \\
\hline Missing & 5 & & 7 & & 13 & & \\
\hline \multicolumn{8}{|l|}{ Hand-arm follow up status } \\
\hline Incomplete follow up & 47 & (39.5) & 51 & $(41.1)$ & 49 & (35.7) & 0.89 \\
\hline Full follow up* & 72 & $(60.5)$ & 73 & (58.9) & 66 & (64.3) & \\
\hline \multicolumn{8}{|l|}{ Neck-shoulder follow up status } \\
\hline Incomplete follow up & 38 & (33.3) & 37 & (31.9) & 39 & (35.8) & 0.82 \\
\hline Full follow up* & 76 & $(66.7)$ & 79 & (68.1) & 70 & (64.2) & \\
\hline
\end{tabular}

FE, Fisher's exact test; JCQ, Job Content Questionnaire.

*Participants who remained in the study for the full duration of their eligibility were classified as "full follow up" (see Methods section for full description).

significant differences between groups with regards to typing speed, job title, the ability to take breaks, or average time spent keying per week.

\section{Compliance with postural interventions}

Compliance with the postural interventions was assessed at the time of the intervention and during two follow up visits (tables 5 and 6). Full compliance (that is, all compliance variables within the established compliance range) with the intervention postures was attained by $25 \%$ of group A and by $38 \%$ of group B participants. The primary reason for noncompliance in group A was that the required elbow difference was impossible to achieve with the participant's workstation.
Incidence of hand/arm and neck/shoulder symptoms by intervention group

Of the 358 arm or hand cohort members followed, 22 (18.5\%) group A participants, 25 (20.2\%) group B participants, and 25 (21.7\%) group C participants reported symptoms (fig 1). A total of 188 participants (53\% of those followed) remained in the cohort for six months of follow up or until reporting incident arm or hand symptoms, 147 (41\% of those followed) were lost during the six month follow up period (refused posture, stopped participating with no reason given, or did not complete forms), and 23 (6\% of those followed) exited the study for another reason (left employer or experienced acute, non-work related arm or hand trauma). Of the 147 lost

Table 4 Diary characteristics by intervention group

\begin{tabular}{|c|c|c|c|c|c|c|c|}
\hline & \multicolumn{6}{|c|}{ Intervention group } & \multirow[b]{3}{*}{ p value } \\
\hline & \multicolumn{2}{|c|}{$A(n=122)$} & \multicolumn{2}{|c|}{$B(n=125)$} & \multicolumn{2}{|c|}{$C(n=115)$} & \\
\hline & Mean & (SD) & Mean & (SD) & Mean & (SD) & \\
\hline Total hours in office (first full week) & 37.99 & $(7.48)$ & 38.90 & (7.47) & 40.17 & (6.44) & 0.07 \\
\hline Total hours on the computer (first full week) & 24.25 & $(11.18)$ & 24.80 & (12.57) & 26.60 & $(10.98)$ & 0.27 \\
\hline Stress (first full week) & 2.88 & (2.04) & 3.55 & (2.47) & 3.48 & (2.33) & 0.04 \\
\hline Total minutes of physical activity (first full week) & 140.04 & $(187.50)$ & 128.59 & (72.83) & 151.87 & $(183.99)$ & 0.61 \\
\hline Minutes of aerobic physical activity (first full week) & 61.88 & (115.78) & 69.11 & $(124.29)$ & 52.83 & (97.93) & 0.54 \\
\hline Minutes of hand intensive activity (first full week) & 71.67 & $(181.90)$ & 68.31 & (223.01) & 74.43 & $(174.04)$ & 0.97 \\
\hline
\end{tabular}




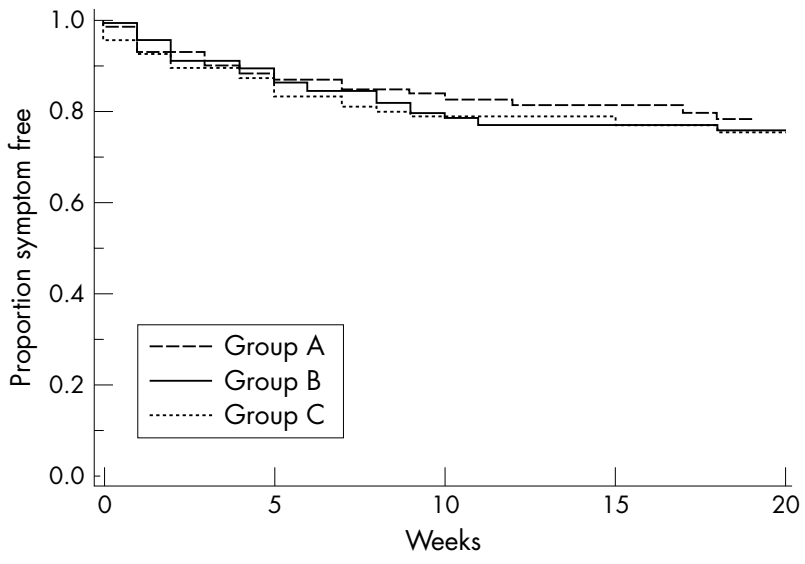

Figure 3 Kaplan-Meier survival curves for the arm and hand cohort.

during six months follow up, 58 (39\%) contributed 12 or more weeks of person-time. Thus, of the original 358 members of the arm or hand cohort, 89 (25\%) were lost to follow up after contributing fewer than 12 weeks of observation. No differences were observed in dropout rates (that is, incomplete follow up) across the three intervention groups (table 3 ).

Of the 339 neck or shoulder cohort members followed, 38 (33.3\%) group A participants, 36 (31.0\%) group B participants, and $33(30.3 \%)$ group C participants reported symptoms (fig 2). A total of 204 participants $(60 \%$ of those followed) remained in the cohort for six months of follow up or until reporting incident arm or hand symptoms, 114 (34\% of those followed) were lost over the six months follow up period (refused posture, stopped participating with no reason given, or did not complete forms) and 21 (6\% of those followed) exited the study for another reason (left employer or experienced acute, non-work related arm or hand trauma). Of the 114 lost during the six months follow up, 44 (39\%) contributed 12 or more weeks of person-time. Thus, of the original 339 members of the neck or shoulder cohort, 70 $(21 \%)$ were lost to follow up after contributing fewer than 12 weeks of observation. No differences were observed in

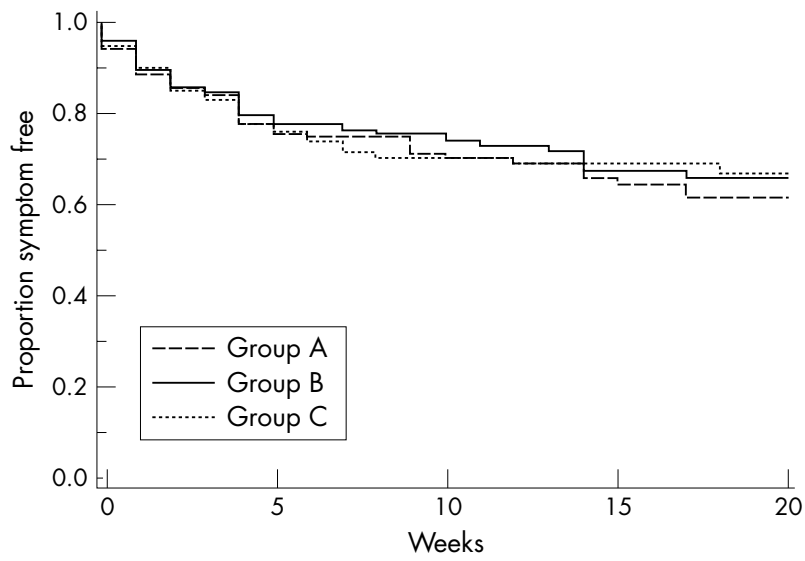

Figure 4 Kaplan-Meier survival curves for the neck and shoulder cohort.

dropout rates (that is, incomplete follow up) across the three intervention groups (table 3 ).

The Kaplan-Meier survival curves for the arm/hand cohort indicated that there were no significant differences in time to symptoms among the three groups (log rank test probability $=0.75$ ) (fig 3 ). When limiting the analysis to only those who were compliant with all of the postural specifications at the initial intervention, there was no difference in time to symptoms between the groups (data not shown). This was also observed when limiting the analysis to only those compliant during the first or second recheck.

The Kaplan-Meier survival curves for the neck/shoulder cohort indicated that there were no significant differences in time to symptoms among the three groups (log rank test probability $=0.84$ ) (fig 4$)$. When limiting the analysis to only those who were compliant with all of the postural specifications at the initial intervention, no statistically significant difference in time to symptoms between the groups was observed (data not shown). This was also observed when limiting the analysis to only those observed to be compliant during the first or second recheck.

\begin{tabular}{|c|c|c|c|c|c|c|}
\hline \multirow[b]{3}{*}{ Compliance variable } & \multicolumn{6}{|c|}{ Number and percentage in compliance by visit } \\
\hline & \multicolumn{2}{|c|}{ Intervention } & \multicolumn{2}{|c|}{ 1st recheck } & \multicolumn{2}{|c|}{ 2nd recheck } \\
\hline & $\mathbf{n}$ & (\%) & $\mathrm{n}$ & $(\%)$ & $\mathrm{n}$ & $(\%)$ \\
\hline Chair & 122 & $(100.0)$ & 119 & $(100.0)$ & 113 & $(100.0)$ \\
\hline Shoulder rest & 121 & (99.2) & 118 & (99.2) & 112 & (99.1) \\
\hline Keyboard wrist rest & 118 & (96.7) & 115 & $(96.6)$ & 109 & (96.5) \\
\hline Edge J & 102 & (83.6) & 104 & (87.4) & 101 & $(89.4)$ \\
\hline Keyboard wrist ulnar deviation & 118 & (96.7) & 106 & (89.1) & 102 & $(90.3)$ \\
\hline Keyboard inner elbow angle & 118 & (96.7) & 114 & $(95.8)$ & 100 & $(88.5)$ \\
\hline Mouse wrist ulnar deviation & 119 & (97.5) & 109 & (91.6) & 108 & (95.6) \\
\hline Mouse wrist extension & 107 & (87.7) & 105 & (88.2) & 100 & $(88.5)$ \\
\hline Monitor head tilt & 106 & (86.9) & 105 & $(88.2)$ & 99 & (87.6) \\
\hline Monitor head rotation angle & 119 & (97.5) & 117 & (98.3) & 112 & (99.1) \\
\hline Elbow difference & 63 & $(51.6)$ & 54 & $(45.4)$ & 56 & $(49.6)$ \\
\hline \multicolumn{7}{|l|}{ Overall compliance } \\
\hline Totally compliant & 31 & (25.4) & 34 & (28.6) & 36 & (31.9) \\
\hline Not compliant in 1 category & 64 & (52.5) & 47 & (39.5) & 42 & (37.2) \\
\hline Not compliant in 2 categories & 17 & (13.9) & 22 & $(18.5)$ & 22 & $(19.5)$ \\
\hline Not compliant in 3 categories & 9 & (7.4) & 13 & (10.9) & 9 & $(8.0)$ \\
\hline Not compliant in 4 categories & 1 & $(0.8)$ & 2 & $(1.7)$ & 2 & (1.8) \\
\hline Not compliant in $\geqslant 5$ categories & 0 & $(0.0)$ & 1 & (0.8) & 2 & $(1.8)$ \\
\hline
\end{tabular}




\begin{tabular}{|c|c|c|c|c|c|c|}
\hline \multirow[b]{3}{*}{ Compliance variable } & \multicolumn{6}{|c|}{ Number and percentage in compliance by visit } \\
\hline & \multicolumn{2}{|c|}{ Intervention } & \multicolumn{2}{|c|}{ 1st recheck } & \multicolumn{2}{|c|}{ 2nd recheck } \\
\hline & $\mathbf{n}$ & (\%) & $\mathrm{n}$ & (\%) & n & (\%) \\
\hline Chair & 125 & $(100.0)$ & 118 & $(100.0)$ & 118 & $(100.0)$ \\
\hline Keyboard wrist rest & 123 & (98.4) & 116 & (98.3) & 116 & (98.3) \\
\hline Eye level & 104 & (83.2) & 102 & (86.4) & 110 & (93.2) \\
\hline Keyboard wrist ulnar deviation & 125 & $(100.0)$ & 116 & (98.3) & 116 & (98.3) \\
\hline Keyboard inner elbow angle & 119 & (95.2) & 109 & (92.4) & 110 & (93.2) \\
\hline Keyboard wrist extension & 98 & $(78.4)$ & 97 & $(82.2)$ & 96 & (81.4) \\
\hline Keyboard shoulder flexion & 99 & (79.2) & 103 & (87.3) & 95 & (80.5) \\
\hline Keyboard shoulder abduction & 118 & (94.4) & 108 & (91.5) & 110 & (93.2) \\
\hline Mouse wrist ulnar deviation & 125 & $(100.0)$ & 118 & $(100.0)$ & 117 & (99.2) \\
\hline Mouse wrist extension & 106 & (84.8) & 101 & (85.6) & 99 & (83.9) \\
\hline Monitor head rotation angle & 122 & (97.6) & 116 & (98.3) & 116 & (98.3) \\
\hline Elbow difference & 100 & $(80.0)$ & 85 & $(72.0)$ & 75 & (63.6) \\
\hline \multicolumn{7}{|l|}{ Overall compliance } \\
\hline Totally compliant & 47 & (37.6) & 50 & (42.4) & 50 & (42.4) \\
\hline Not compliant in 1 category & 41 & (32.8) & 29 & (24.6) & 31 & (26.3) \\
\hline Not compliant in 2 categories & 24 & (19.2) & 25 & (21.2) & 18 & (15.3) \\
\hline Not compliant in 3 categories & 7 & $(5.6)$ & 8 & $(6.8)$ & 10 & (8.5) \\
\hline Not compliant in 4 categories & 4 & (3.2) & 6 & (5.1) & 6 & (5.1) \\
\hline Not compliant in $\geqslant 5$ categories & 2 & (1.6) & 0 & $(0.0)$ & 3 & (2.5) \\
\hline
\end{tabular}

Multivariate analyses controlling for gender, age, and hours keying during the previous week revealed no differences in time to symptoms between group A or group B when compared to group $\mathrm{C}$ for either hand or arm symptoms (group A: HR = 0.92, 95\% CI 0.49 to 1.71; group B: HR = 1.05, 95\% CI 0.58 to 1.90 ) or neck or shoulder symptoms (group A: $\mathrm{HR}=1.07,95 \%$ CI 0.64 to 1.80 ; group $\mathrm{B}: \mathrm{HR}=1.00,95 \% \mathrm{CI}$ 0.60 to 1.68 ).

Because of concerns about correlated outcomes, additional proportional hazards analyses were performed in which time to first event was included as the dependent variable. Forty participants contributed events to both the neck/shoulder and the arm/hand analyses. Of those, 18 had the two events simultaneously and 22 had them in different weeks. The results were unchanged from the models in which all participants were included (results not shown).

\section{DISCUSSION}

In this randomised controlled trial, no significant differences in time to symptoms were observed among the three interventions nor were any trends suggestive of an effect observed. This result was not expected, as a recently completed prospective observational study of participants recruited from the same population of computer users suggested moderate effects of posture on symptoms. Although the intervention postures were not shown to reduce the risk of musculoskeletal symptoms in this study, it is possible that a true effect was obscured by other factors.

One possible source of bias in the observed results is confounding. For several reasons, we do not believe that the absence of an association was the result of confounding. First, the likelihood of substantial differences in important covariates across intervention groups was minimised by randomly allocating study participants to each of the three groups. Inspection of the results shows that most important covariates were distributed similarly across intervention groups. Second, we performed multivariate analyses of associations between time to symptoms and intervention group while controlling for gender, age, and hours keying during the previous week. These analyses revealed no significant associations between intervention group and time to symptoms for either hand/arm or neck/shoulder symptoms. Additional adjustment for height, BMI, race, education, handedness, job title, and a history of musculoskeletal symptoms did not alter this result.

Another possible reason for the absence of effects was our inability to fully implement the intervention among the study participants. Fewer than one third of group A participants and fewer than one half of group B participants were fully compliant with the interventions. It is possible that differences in incidence would have been observed between groups had the intervention postures been implemented more completely. Non-compliance with the intervention postures may not fully account for the absence of findings, however. While full compliance was uncommon, nearly $70 \%$ of both intervention groups were able to comply with 10 of 11 compliance categories. Thus, participants were able to achieve substantial, if not full, compliance. We also performed an analysis restricted to participants who achieved full compliance and observed no meaningful differences between the groups, although numbers were small.

Another possible reason for the absence of an observed result was poor ascertainment of health outcome. We consider this unlikely. The method of ascertaining health outcome was similar to that used in previous investigations $^{1012}$ in which associations were observed between postures, demographic characteristics, work organisation factors, and symptoms. Indeed, in the current study, two factors that have been observed in past investigations to be associated with symptoms - that is, female gender and past history of symptoms, were associated with the symptom outcomes used in the current study.

Some prior studies of associations between work activities and musculoskeletal outcomes have been criticised for using symptoms alone (as opposed to symptoms and physical examination findings) as the health outcome, as was done in the current study. In a previous study, ${ }^{10}$ however, we observed that risk factors for musculoskeletal symptoms and risk factors for musculoskeletal disorders among a sample obtained from the same study population were very similar. We believe that had physical examination findings been used to identify health events (in addition to symptoms), the results would not have been meaningfully different.

Several other investigators have reported on the results of experimental or quasi-experimental studies of the effect of various interventions on musculoskeletal outcomes among 
computer users, although only a few have examined specific postural interventions. Aarås and colleagues ${ }^{16}$ examined the effect on musculoskeletal symptoms of a computer workstation that allowed computer users to support the entire forearm on the table/desk top while keying among approximately 150 study participants. Neck and shoulder pain frequency and intensity were lower among those who received the forearm support compared to similar workers who did not. A long term follow up of the participants ${ }^{17}$ showed continued reductions in shoulder discomfort in one of the two groups followed for six years and a third group followed for a shorter period. In comparison to the current study, the investigators had greater opportunity to modify workstations to achieve the desired intervention.

In a number of published studies, multiple interventions were implemented simultaneously, making the effect of specific components difficult to assess. For example, Robertson and $\mathrm{O}^{\prime} \mathrm{Neill}^{18}$ compared the prevalence of musculoskeletal symptoms among those provided with new workstations and ergonomic training or new workstations alone to those who received neither. Nelson and Silverstein ${ }^{19}$ compared office workers who were relocated to a new building with modern adjustable workstations to those who had no intervention. In both studies, lower rates of musculoskeletal outcomes were observed among members of the intervention groups. However, the specific changes responsible for the effect could not be ascertained nor can the role of placebo be excluded.

Other intervention studies are less directly comparable to the current study because of substantial differences in methods. For example, Ketola and colleagues ${ }^{20}$ and Mekhora and colleagues ${ }^{21}$ examined the effect of workstation interventions among computer users who were actively symptomatic at the time of recruitment. Results observed among persons selected on the basis of symptoms may not be comparable to those obtained from a sample of participants free from symptoms at entry into the study. Brisson and colleagues $^{22}$ compared the effect of an ergonomic training programme on selected exposure variables and musculoskeletal health outcomes among 284 workers and 343 referents who did not receive the training. Among participants less than 40 years of age, substantial decreases in the prevalence of symptoms and physical examination findings were observed among both intervention and reference participants, although the effect size was larger among intervention participants. Among participants 40 years of age or greater, small increases in symptoms and examination findings among both intervention and reference participants were observed.

In summary, the results of this study suggest that caution should be exercised when making recommendations regarding posture as the sole means of minimising risk of musculoskeletal symptoms among computer users. Such caution appears warranted as recommendations for postural modification seems to be the mainstay of many ergonomics programmes intended for computer users. Effects of postural interventions may be more readily observed in future studies if workstations are more easily adjustable to allow for more complete compliance with postural interventions.

\section{ACKNOWLEDGEMENTS}

The investigators are grateful to the Steelcase Corporation for their donation of LEAP chairs for use among intervention participants.
A substantial portion of the data for this study were collected by Ms Alicia Edwards and Ms Jennifer Vaughn. Databases and data management programs were written by Ms Eileen Gentry.

\section{Authors' affiliations}

F Gerr, Department of Occupational and Environmental Health, College of Public Health, University of lowa, lowa City, lowa, USA

M Marcus, L Hannan, D Kleinbaum, Department of Epidemiology,

Rollins School of Public Health, Emory University, Atlanta, Georgia, USA

C Monteilh, Department of Environmental and Occupational Health,

Rollins School of Public Health, Emory University, Atlanta, Georgia, USA

D Ortiz, Georgia Tech Research Institute, Georgia Institute of

Technology, Atlanta, Georgia, USA

Funding: this study was funded by the US National Institute for Occupational Safety and Health

Competing interests: none declared

\section{REFERENCES}

1 Gerr F, Letz R, Landrigan PJ. Upper-extremity musculoskeletal disorders of occupational origin. Annu Rev Public Health 1991; 12:543-66.

2 Mani L, Gerr F. Work-related upper extremity musculoskeletal disorders. Primary Care Clinics in Office Practice 2000;27:845-64.

3 US Bureau of Labor Statistics. http://www.bls.gov/iif/oshwc/osh/os/ osch0024.pdf, 2003.

4 US Census Bureau. Computer use in the United States, current population reports. September 1999:20-522.

5 OSHA. Working safely with video display terminals. Revised (OSHA 3092) US Department of Labor: Occupational Safety and Health Administration, 1997.

6 Electronic News. http://www.reed-electronics.com/electronicnews/contents/ pdf/cominuse.pdf, 2004

7 Gerr F, Marcus M, Ortiz D. Methodological limitations in the study of video display terminals and upper-extremity musculoskeletal disorders. Am J Ind Med 1996;29:649-56.

8 Karasek R. Job demands, job decision latitude and mental strain: implications for job design. Admin Sci Quart 1979;24:285-308.

9 Fleiss JL, Levin B, Cho Paik M. Statistical methods for rates and proportions, 3rd edn. New Jersey: John Wiley and Sons, 2003.

10 Marcus M, Gerr F, Monteilh C, et al. A prospective study of computer users: II. Postural risk factors for musculoskeletal symptoms and disorders. Am J Ind Med 2002;41:236-9

10a Carter JB, Banister EW. Musculoskeletal problems with VDT work: a review. Ergonomics 1994; 37:1623-48.

11 Ortiz DJ, Marcus M, Gerr F, et al. Measurement variability in upper extremity posture among VDT users. Appl Ergon 1997;28:139-43.

12 Gerr F, Marcus M, Ensor C, et al. A prospective study of computer users: I. Study design and incidence of musculoskeletal symptoms and disorders. Am J Ind Med 2002;41:221-35.

13 Cox DR, Oakes D. Analysis of survival data. New York: Chapman and Hall, 1984.

14 Kalbfleisch JD, Prentice RL. The statistical analysis of failure time data. Wiley Series in Probability and Statistics. New York: Wiley and Sons, 1980.

15 Kleinbaum D. Survival analysis: a self-learning text. New York: SpringerVerlag, 1996

16 Aarås A, Horgen G, Biørset $\mathrm{HH}$, et al. Musculoskeletal, visual and psychosocial stress in VDU operators before and after multidisciplinary ergonomic intervention. Appl Ergon 1998;29:334-54.

17 Aarås A, Horgen G, Bjørset HH, et al. Musculoskeletal, visual and psychosocial stress in VDU operators before and after multidisciplinary ergonomic intervention. A 6 years prospective study-Part II. Appl Ergon 2001;32:559-71.

18 Robertson M, O'Neill MJ. Reducing musculoskeletal discomfort: effects of an office ergonomics workplace and training intervention. Int J Occup Safety Ergon 2003;9:491-502.

19 Nelson NA, Silverstein BA. Workplace changes associated with reduction in musculoskeletal symptoms in office workers. Human Factors 1998;40:337-50

20 Ketola R, Toivonen R, Häkkänen $M$, et al, and the expert Group in Ergonomics. Scand J'Work Environ Health 2002;28:18-24.

21 Mekhora K, Liston CB, Nanthavanij S, et al. The effect of ergonomic intervention on discomfort in computer users with tension neck syndrome. Int J Ind Ergon 2000;26:367-79.

22 Brisson C, Montreuil S, Punnett L. Effects of an ergonomic training program on workers with video display units. Scand J Work Environ Health $1999 ; 25: 255-63$ 